Article

\title{
Application of CFD for Numerical Analysis of Liquid- Liquid Mixing in T-Shape Mixer Using Ansysfluent
}

\author{
Abdulmumuni Aliyu 1, Taufan Marhaendrajana ${ }^{2}$ and Yazid Bindar ${ }^{2, *}$ \\ Dept. of Petroleum Engineering, Institute of Technology Bandung; tmarhaendrajana@tm.itb.ac.id \\ Dept. of Chemical Engineering, Institute of technology Bandung; ybybyb@fti.itb.ac.id \\ * Correspondence: abdulmumeen720@gmail.com; Tel.: +2348148257878
}

\begin{abstract}
Computational fluid dynamics (CFD) has, in the last decade, being an essential problem solving tool in industries such as pharmaceutical, pulp, petrochemical as well as Oil and Gas processing. The use of CFD for mixer design is unpopular in many countries in Africa. Therefore, this study investigates the characteristics of Brine-Surfactant mixing in a horizontal pipeline using CFD. The CFD is conducted by AnsysFluent software (licensed). A T-junction pipe is created and meshed with unstructured tetrahedral elements using design modeler. Discretization is done by Finite Volume Method (FVM), cell-centered scheme with Second-Order Upwind Scheme. The pressure term is introduced into the continuity equation by SIMPLE (Semi-Implicit Method for Pressure Linked Equations) algorithm. The kinetic epsilon model, also known as k-e model is administered to define the properties of the fluid and geometry, such as velocity, species mole fraction, pipe diameter. The boundary conditions is selected based on filed data. The rate of fluid flow in the primary region is $650 \mathrm{bbl} /$ day at $400 \mathrm{psi}$ in 4 in diameter pipeline, which is $100 \mathrm{~m}$ long. The numerical simulation was based upon the governing equations such s continuity, Navier's stoke, energy as well as specie transport equations. The findings shows that higher concentration results in increased mixing time, while $2 \%$ conc. of surfactant reaches homogeneity in 20 minutes at 72 meters of the pipe length. The result validated with field detail and the empirical result from literature, and is consistent. This study provide insight on industrial mixer design, chemical injection system, as well as gas pipeline design and optimization, especially in multiphase scale transport.
\end{abstract}

Keywords: CFD, Pipeline, Liquid-liquid Mixing, Surfactant Injection

\section{Introduction}

The technology of mixing is an important phenomena that has been used in many industrial applications such as chemical plants, oil refinery, pulp manufacturing, petrochemical, gas treatment e.t.c Mixing basically involves changing of substance from a non-uniform system into a uniform one. The key parameters that characterize blending process include degree of mixing, mixing time, mixing length, optimal diameter, as well as the species mole fractions. The vessel in which mixing is carried out plays a vital role in understanding those parameters. The most common vessel often administered is stirred tank mixer since it offers easy access to determining the mixing parameters. However, the phenomenon is quite challenging due to complexity of the impeller design. Therefore, mixing in pipe line geometry by injection of indicator at the T-junction can be helpful in achieved mixing objective by turbulence. This technique is based on empirical method, and the process was reported to have been associated with high cost and time consuming. Alternatively, industries are currently considering the use of CFD as a simulation tool to design mixing system such as t-shape mixer. It is very realistic and capable of solving two-phase or multiphase flow and more complex geometry problems as well as performance analysis [1-3].

Many researchers have applied CFD as simulation tool to perform fluid flow related studies, including miscible liquid mixing. Zalc, J. M. et al studied behavior of fluid flow and Mixing in an SMX Static Mixer [4]. Eswara, A. K. carried out Analysis of Fluid Structure Interaction in Mixing 
Fluids [5]; Abdolkarimi, V. and Ganji, H. researched on CFD Modeling of Two Immiscible Fluids Mixing in a Commercial Scale Static Mixer [6]; Joanna, K. worked on CFD Modelling of the Fluid Flow Characteristics in an External-Loop Air-Lift Reactor [7]. However, none of these reports has given attention to CFD application in Enhanced Oil Recovery assist system that involves surfactant and brine mixing analysis. Therefore, this study focuses on design of liquid-liquid mixing in EOR system using Computational Fluid Dynamics (CFD). Also, we investigate the flow properties such as volume fraction profile, average pressure across the pipeline cross section, as well as the velocity profile along the radius of different flow patterns of viscous surfactant-brine two-phase flow through a horizontal pipeline to obtain the mixing length and time of homogeneity. The simulation is carried out using AnsysFLUENT based upon the governing equations such as continuity, Navier's stoke, energy as well as specie transport equations. The simulation results is processed and utilized for optimization of mixing time and length of homogenous mixture.

\section{Numerical Models and Simulation}

The numerical model developed in this study include a number of equations ranging from continuity equation through chemical reaction models. The continuity and Navier-Stokes equations describe the state of flow solved for all flows in CFD modelling. The mathematical model is used to obtain a set of partial differential equations. The partial differential equation is then discretized by application of finite volume method [8-10]. These equations are explained in equation (1) through (13) in the following sub sections. The equation for conservation of mass, or continuity equation, can be written as:

$$
\frac{\partial \rho}{\partial \mathrm{t}}+\nabla \cdot(\rho \overrightarrow{\mathrm{V}})=0
$$

The right side of equation (1) shows that there is no source (Sm) or mass added to the continuous phase. Where $\rho$ density is is time and $\mathrm{V}$ is velocity field. The conservation of momentum in stationary reference frame is described by equation (2).

$$
\rho \frac{\partial \vec{V}}{\partial t}+\rho(\vec{V} \cdot \nabla) \vec{V}=-\nabla \rho+\rho \vec{g}+\nabla \cdot \tau_{i j}
$$

Where $\mathrm{p}$ is the static pressure, $\tau$ is the stress tensor, $\rho \mathrm{g}$ and $\mathrm{F}$ are the gravitational body force and external body force respectively in the model dependent source term. Equation (2) is known as Navier-Stokes equation. The equation is incompressible, and can be expressed in three 3D Cartesian as:

$$
\begin{aligned}
& \text { x-d: } \rho\left(\frac{\partial u}{\partial t}+u \frac{\partial u}{\partial x}+v \frac{\partial u}{\partial y}+w \frac{\partial u}{\partial z}\right)=-\frac{\partial p}{\partial x}+\rho g_{x}+\mu\left(\frac{\partial^{2} u}{\partial x^{2}}+\frac{\partial^{2} u}{\partial y^{2}}+\frac{\partial^{2} u}{\partial z^{2}}\right) \\
& \text { y-d: } \rho\left(\frac{\partial v}{\partial t}+u \frac{\partial v}{\partial x}+v \frac{\partial v}{\partial y}+w \frac{\partial v}{\partial z}\right)=-\frac{\partial p}{\partial y}+\rho g_{y}+\mu\left(\frac{\partial^{2} v}{\partial x^{2}}+\frac{\partial^{2} v}{\partial y^{2}}+\frac{\partial^{2} v}{\partial z^{2}}\right) \\
& \text { z-d: } \rho\left(\frac{\partial w}{\partial t}+u \frac{\partial w}{\partial x}+v \frac{\partial w}{\partial y}+w \frac{\partial w}{\partial z}\right)=-\frac{\partial p}{\partial z}+\rho g_{z}+\mu\left(\frac{\partial^{2} w}{\partial x^{2}}+\frac{\partial^{2} w}{\partial y^{2}}+\frac{\partial^{2} w}{\partial z^{2}}\right)
\end{aligned}
$$

The energy equation that describe fluid flow in the pipeline is represented by equation (6)

$$
\frac{\partial}{\partial t} \int e * \rho d \forall+\int\left(\breve{u}+\frac{p}{\rho}+\frac{V^{2}}{2}+g z\right) \rho V \cdot \check{n} d A=Q_{\text {net in }}+W_{\text {net } \iota n}^{\cdot}
$$

Where $Q_{\text {net in }}$ and $W_{\text {net in }}^{\cdot}$ stand for energy input and work respectively. To solve the flow equations for turbulent flow, the direct numerical simulations and $k-\varepsilon$ are applied. These equations are essential for mesh configuration as in equation (7) though (10) shown as follow.

$$
\begin{gathered}
\kappa=\frac{1}{2}\left(\overline{u^{\prime 2}}+\overline{v^{\prime 2}}+\overline{w^{\prime 2}}\right) \\
\epsilon=v\left[\left(\frac{\partial u^{\prime}}{\partial x}\right)^{2}+\left(\frac{\partial u^{\prime}}{\partial y}\right)^{2}+\left(\frac{\partial u^{\prime}}{\partial z}\right)^{2}+\left(\frac{\partial v^{\prime}}{\partial x}\right)^{2}+\left(\frac{\partial v^{\prime}}{\partial y}\right)^{2}+\left(\frac{\partial v^{\prime}}{\partial z}\right)^{2}+\left(\frac{\partial w^{\prime}}{\partial x}\right)^{2}+\left(\frac{\partial w^{\prime}}{\partial y}\right)^{2}+\left(\frac{\partial w^{\prime}}{\partial z}\right)^{2}\right]
\end{gathered}
$$

Where $\mathrm{k}$ and $\in$ are turbulent kinetic energy and turbulent energy dissipation rated respectively.

$$
\begin{aligned}
& y^{+}=\frac{\rho \operatorname{luy}_{p}}{\mu} \\
\text { Where; } & u=\sqrt{\frac{\tau_{\mathrm{w}}}{\rho_{\mathrm{w}}}}
\end{aligned}
$$


$\mathrm{Y}+$ is a mesh-dependent dimensionless distance that quantifies the degree of the wall layer resolved. $\mathrm{u}$ is the friction velocity and $\mathrm{Yp}$ is the distance to the wall. The mathematical model for mixing is largely dependent on the species transport and finite rate chemistry of the reactants [11]. The generalized chemical species conservation equation when applied to multiphase mixing is shown by equation (11).

$$
\frac{\partial\left(\rho^{q} \alpha^{q} Y_{l}{ }^{q}\right)}{\partial t}+\nabla \cdot\left(\rho^{q} \alpha^{q} v^{q} Y_{l}^{q}\right)=-\nabla \cdot \alpha^{q} J_{l}{ }^{q}+\alpha^{q} \mathrm{R}_{l}{ }^{q}+\alpha^{q} S_{l}{ }^{q}+\sum_{p=1}^{n}\left(m_{p^{i} q^{j}}-m_{q^{j} p^{i}}\right)+\mathrm{R}
$$

Where $\mathrm{R}_{l}{ }^{q}$ is the rate of production of homogeneous species I is by chemical for phase $\mathrm{q}, m_{p^{i} q^{j}}$ is the mass transfer source between I and $\mathrm{j}$ from phase $\mathrm{q}$ to $\mathrm{p}$, and $\mathrm{R}$ is the heterogeneous reaction rate. In addition, $\alpha^{q}$ is the volume fraction for phase $\mathrm{q}$ to $S_{l}{ }^{q}$ is rate of creation by addition from the dispersion phase plus any user-defined sources [12]. For blending mixture without reaction taking place during the mixing process, equation (12) can best describe the process.

$$
\frac{\partial\left(\rho^{q} \alpha^{q} Y_{l}{ }^{q}\right)}{\partial t}+\nabla \cdot\left(\rho^{q} \alpha^{q} v^{q} Y_{l}^{q}\right)=-\nabla \cdot \alpha^{q} J_{l}^{q}+\alpha^{q} S_{l}^{q}+\sum_{p=1}^{n}\left(m_{p^{i} q^{j}}-m_{q^{j} p^{i}}\right)
$$

\section{Simulation Detail}

This study explores computational fluid dynamics for solving mixing problem, which involves brine-surfactant mixing in a horizontal pipeline. The software administered in performing CFD is

\begin{tabular}{|c|c|}
\hline & CFD method \\
\hline & $\begin{array}{l}\text { - Horizontal pipe sketch } \\
\text { - T-junction pipe design }\end{array}$ \\
\hline & $\begin{array}{l}\text { - Unstructured mesh of the geometry created } \\
\text { - Refining the mesh }\end{array}$ \\
\hline & $\begin{array}{l}\text { - Choosing model } \\
\text { - Selecting material and fluid flow } \\
\text { - Specify boundary condition } \\
\text { Discretization and Initialization of the model }\end{array}$ \\
\hline tion & $\begin{array}{l}\text { - Specify number of iteration } \\
\text { - Calculation }\end{array}$ \\
\hline sults & - Post processing of results \\
\hline
\end{tabular}
Ansys Fluent version: 17.1.0.2016040120. The steps followed in this work is illustrated in figure 1.

Figure 1. The steps to perform CFD of liquid-liquid mixing in AnsysFluent.

The data related to geometry includes diameter and length of the main, as well as the dimension of the injection, branched pipe. These data is contained in table 1 .

Table 1. The pipe geometry data.

\begin{tabular}{ll}
\hline Item & Data \\
\hline$D$ & 4in \\
\hline
\end{tabular}




\begin{tabular}{ll}
\hline$L$ & $100 \mathrm{~m}$ \\
$D$ & $2 \mathrm{in}$ \\
$n L$ & $1 \mathrm{~m}$ \\
t-angle & 90 \\
Material type & Steel \\
\hline
\end{tabular}

The pipeline is designed to transport brine with injected surfactant. The data that describe fluid flow are flow rate, velocity, viscosity as well as the density of both primary and secondary fluid in the pipeline. The data used in this study are presented in table 2 .

Table 2. Physical properties of the fluid.

\begin{tabular}{cll}
\hline $\begin{array}{c}\text { Fluid } \\
\text { property }\end{array}$ & Brine & Surfactant \\
\hline Flow rate & $637 \mathrm{bbl} /$ day & $13 \mathrm{bb} /$ day \\
Density & $1000 \mathrm{~kg} / \mathrm{cum}$ & $984 \mathrm{~kg} / \mathrm{cum}$ \\
Viscosity & $1.05 \mathrm{cp}$ & 0.56 \\
Temperature & $338 \mathrm{k}$ & 370 \\
Fraction & 0.98 & 0.02 \\
Colour & White & White \\
\hline
\end{tabular}

In any Computational Fluid Dynamics (CFD) problem, it is essential to define its boundary conditions in a realistic manner. This study adopts no-slip boundary condition, which manifests in the confined fluid flow problems is the Wall. This type of boundary condition is used where boundary values of pressure are known and the exact details of the flow distribution are unknown. This includes pressure inlet and outlet conditions mainly. Transient problems require initial conditions where initial values of flow variables are specified at various nodes in the flow domain. The distribution of all flow variables are specified at the inlets and outlet boundary conditions, mainly flow velocity. The normal component is set to zero straightaway while the tangential component is set to the velocity of the wall. This condition is considered appropriate conditions for velocity components at the wall. Table 3 shows the boundary condition applied in this study using different fluid flow rate as the key basis.

Table 3. The boundary condition for CFD simulation in this study.

\begin{tabular}{lllll}
\hline $\mathbf{S} / \mathbf{N}$ & Component & $\mathbf{1 0} \% \mathbf{v}(\mathbf{m} / \mathbf{s})$ & $\mathbf{5 \% v}(\mathbf{m} / \mathbf{s})$ & $\mathbf{2 \% v ( m / s )}$ \\
\hline 1 & Brine & 0.1328 & 0.1470 & 0.1446 \\
2 & Surfactant & 0.0148 & 0.0074 & 0.00296 \\
\hline
\end{tabular}

In this research, it appears that computational fluid dynamic is solving complex differential equation. For the sake of simplicity, an assumption was made within logical range of the study. Since the brine and surfactant solution is predominantly water based, the flow is assumed to be in single phase. In this regard, steady state flow is assumed.

\section{Result and Discussion}

\subsection{Geometry and Discretized mesh}


The medium in which surfactant and brine mixing was carried out is depicted by figure 2.The geometry was designed by modeler and it consists of two sections of steel pipe. The main section is $105 \mathrm{~m}$ length and the auxiliary section is $1 \mathrm{~m}$ connecting at about $5 \mathrm{~m}$ from the inlet. Both sections have 4 inch diameter each. The total surface area is 31766 square meters while volume is 78,992 cubic meter. The simulations results are presented and analyzed using various sensitivity data by varying the field parameters with surfactant in three specie concentration. In other to perform discretization of the model equation, the geometry was meshed. The computational geometry was discretized using an unstructured mesh with tetrahedral elements. The Grid algorithm was used to generate the mesh. Very small cell size is needed for this case to get good convergence. The size of each cell is $0.007 \mathrm{~m}$. The number of tetrahedrons element is 694436 with 135432 nodes. The smooth transition used has ratio 0.272 , and has a growth rate of 1.2. A Finite Volume Method (FVM) was used to convert the governing equations to algebraic equations. A cell-centered scheme was used in the process of discretization. Values of cell faces were computed using a Second-Order Upwind Scheme [13].The Second-Order Upwind Scheme is typically suggested as a requirement to procure accurate results with unstructured meshing schemes Pressure-velocity coupling is an issue that must be addressed during the process of obtaining a sequential solution to the momentum and continuity equations. The SIMPLE (Semi-Implicit Method for Pressure Linked Equations) algorithm has been used to introduce a pressure term in the continuity equation. The SIMPLE algorithm was chosen as the consistent approach to pressure-velocity coupling across the range of operating flow rates. The criterion for iterative convergence was set at $1 \times 10-9$, which is a typical constraint for multiphase flows that consider chemical kinetics [14, 15].

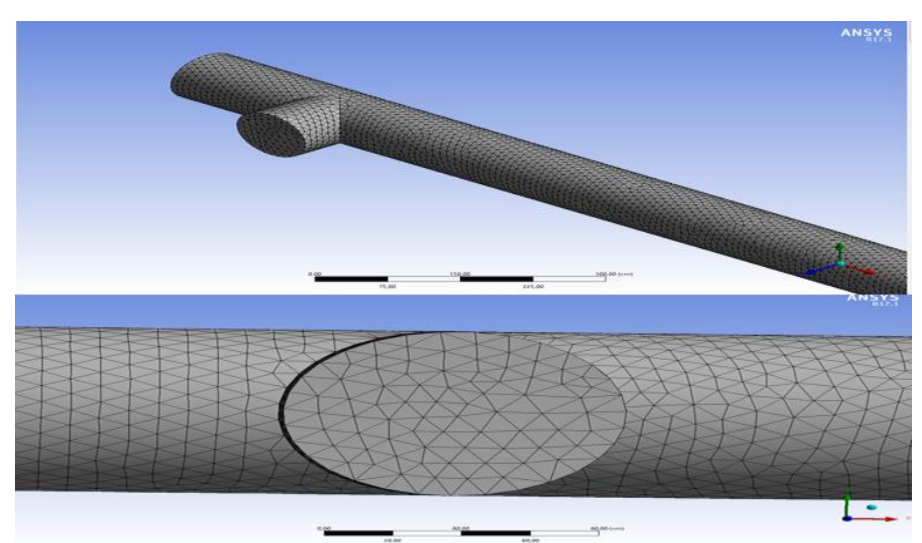

Figure 2. The tetrahedral meshed geometry of $100 \mathrm{~m}$ t-shape pipeline in which mixing is done.

\subsection{Mixing phase}

The numerical simulation of the mixing process between two fluids in the T-type is shown in figure $3(\mathrm{a})$ through $3(\mathrm{f})$, with various concentration of surfactant species such as $10 \%, 5 \%$ and $2 \%$ concentrations with intents to see the sensitivity of the mixture to change in specie. The surfactant-brine mixing involves the two inlet fluids with injected surfactant at the branched arm, which is $1 \mathrm{~m}$ to the $100 \mathrm{~m}$ horizontal pipe in which the brine water is running. The volumetric flow rates at $1 \mathrm{~m}$ inlets is determined by the concentration of surfactant being considered. The hydraulic diameter $(\mathrm{d})$ of the mixing channel and the kinematic viscosity of water. The change in boundary conditions, for example velocity, the pressure profile as result of flow, as well as the phase species transport profile have been displayed with contours. The figure $3(a)$ is the contour representation of path lines of surfactant injected in the T-junction arm of the geometry. The color seen in the geometry depicts flow change effect across the pipeline. The phase change variation valued in range between 0 and 1 , with 0 having deep blue color at lowest fraction and 1 having red at highest fraction of surfactant. In this section, $10 \%$ concentration of 
surfactant is injected, fully filled on the T-junction while the primary line of the geometry is filled with $100 \%$ brine, meaning surfactant concentration is zero in the region. As brine and surfactant meet at the junction, mixing begin due to turbulence and density difference between the substances. Right in the corner of the T-junction, a stratified flow is seen with surfactant specie appears to be mixing slightly.

A gross mixing of brine and surfactant depicted by light green color after about $25 \mathrm{~m}$ from the junction can be seen while the stratified phase remain through the full length of the pipe line. It can be deduced from this that there no homogenous mixture of the fluid at 100 meters. Therefore, in other to get the fluid mixed, two things could be done: a static mixer may be designed and installed in the mixer, and the length of this pipe could be extended longer. The 2Dimentional view of the scenario of $10 \%$ surfactant specie concentration in presented in figure 3 (b). The side view shows that surfactant injection is $100 \%$ on the T-junction arm of the geometry. No air is seen in any part of the pipe since red color covers the whole circumference of the pipe. The figure 3(c) is the contour representation of path lines of $5 \%$ concentration of surfactant being injected into the T-junction arm of the geometry. The $5 \%$ concentration of surfactant injected is fully filled on the T-junction while the primary line of the geometry is filled with $100 \%$ brine. The brine and surfactant begin mixing right at the junction as shown by color change in the region. This occurred as a result of turbulence and density difference between the substances. Again, a stratified flow is seen with surfactant specie appears in the bottom of the pipe. While molecular mixing of the component continue throughout the full length of the pipe, it is evident that homogenous mixture cannot be achieved with $5 \%$ concentration of injected surfactant. Therefore, it could be recommended that either a static mixer is installed or the length of this pipe is extended longer.

The 2-Dimentional view of the case of $5 \%$ surfactant specie concentration is presented in figure 3(d). The side view shows that surfactant injection is $100 \%$ on the T-junction arm of the geometry. No air is seen in any part of the pipe since red color covers the whole circumference of the pipe. The figure 3(e) is the contour representation of path lines of surfactant injected through the T-junction arm of the geometry. The color seen in the geometry depicts flow change effect across the pipeline. The $2 \%$ concentration of surfactant injected is seen to have partially filled the pipe at the T-junction. This is a sign that about $45 \%$ of the junction pipe is air filled. In addition, while the primary line of the geometry is filled with $100 \%$ brine, the surfactant concentration is zero in the region. As brine and surfactant meet at the junction, mixing occurred as a result of turbulence and density difference between the substances. Stratified flow is seen for as long as 10 meters from the junction while mixing appeared to be reasonably well in $2 \%$ concentration injection. The mixing level increases with increased pipe position, and it continued until the green color begin to disappear toward the end of the pipe length. This happened at 72 meter length of the pipe. Therefore, $2 \%$ surfactant concentration could be selected from this sensitivity as the appreciate mole fraction for the mixing for homogenous mixture using this geometry specification.

The 2-Dimentional view of the scenario of $2 \%$ surfactant specie concentration is shown in figure $3(\mathrm{f})$. The side view shows that surfactant injection is $100 \%$ on the T-junction arm of the geometry. There is air mixing in the arm region of the T-junction. Quick mixing is seen from this view while stratified flow is obvious for certain length of the pipe. 


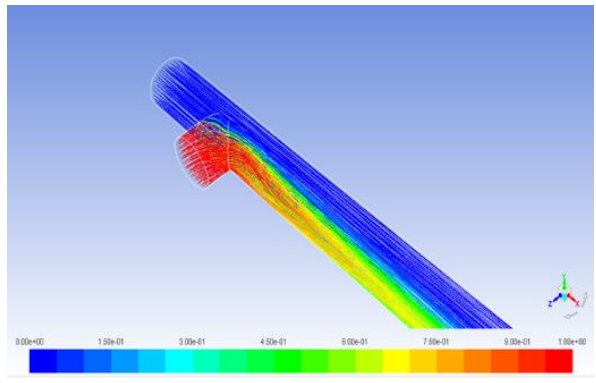

(a)

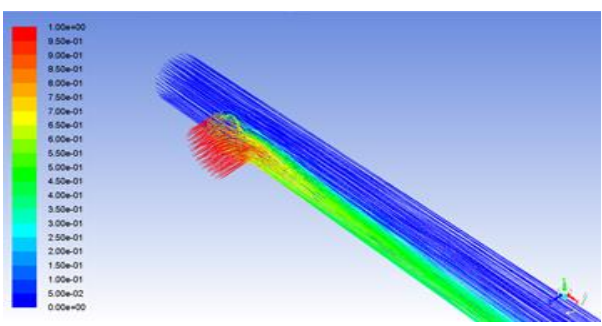

(c)

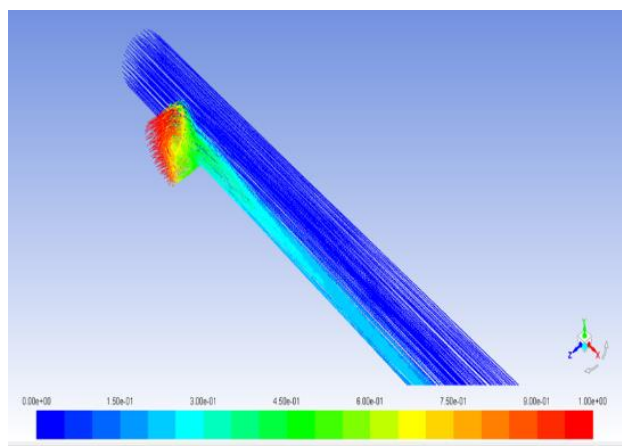

(e)

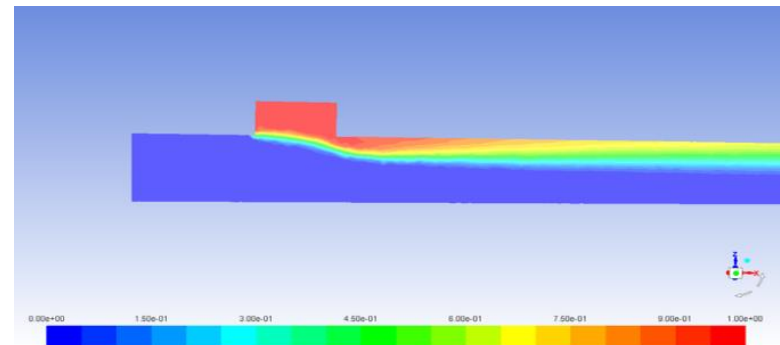

(b)

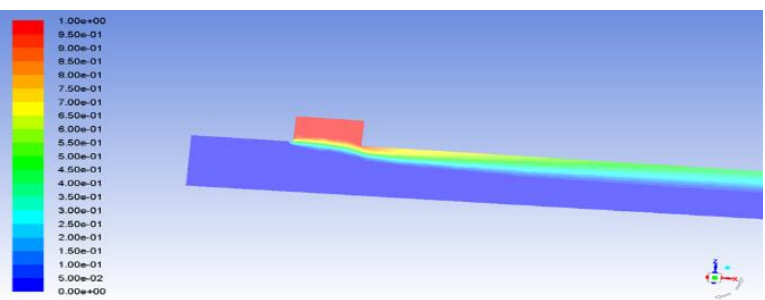

(d)

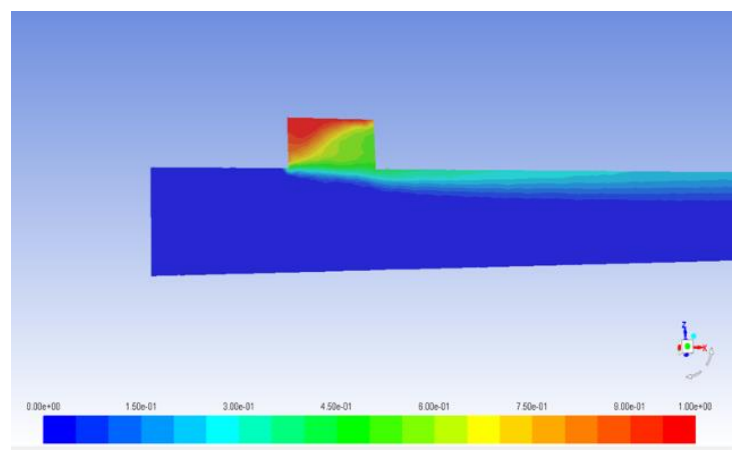

(f)

Figure 3. (a) the contour plots of surfactant brine species at $10 \%$ concentration. (b) The 2-D contour plots of surfactant brine species at 10\% concentration. (c) The contour plots of surfactant brine species at 5\% concentration. (d) The 2-D contour plots of surfactant brine species at 5\% concentration. (e) The contour plots of surfactant brine species at $2 \%$ concentration. (f) The 2-D contour plots of surfactant brine species at $2 \%$ concentration.

The isosurface of mole fraction variable is created to view the result on cells that have a constant value. This was performed based on $\mathrm{x}, \mathrm{y}, \mathrm{z}$ coordinate of the cross section of the pipe geometry. The isosurface of surfactant brine mixing phenomenal understudies for different surfactant concentration such as $10 \%, 5 \%$ and $2 \%$ are shown in figure 4 (a), through $4(\mathrm{c})$. The isosurface of mole fraction variable is created to view the result on cells that have a constant value. This was performed based on $\mathrm{x}, \mathrm{y}, \mathrm{z}$ coordinate of the cross section of the pipe geometry. In figure 4 (a), isosurface contour of $10 \%$ surfactant concentration was taken at different position such $20 \mathrm{~m}, 50 \mathrm{~m}, 80 \mathrm{~m}$ and $100 \mathrm{~m}$. It is seen that four layers are form in the pipe with pink color showing surfactant dominants region in the lower part while deep blue show the region of brine. The fact that no layer disappeared at $100 \mathrm{~m}$ length shows that homogenous mixture is not achieve with the injected concentration of surfactant. Figure $4(\mathrm{~b})$ is the isosurface contour of $5 \%$ surfactant concentration at positions such as $20 \mathrm{~m}, 30 \mathrm{~m}, 40 \mathrm{~m}, 50 \mathrm{~m}, 60 \mathrm{~m}, 70 \mathrm{~m}, 80 \mathrm{~m}, 90 \mathrm{~m}, 100 \mathrm{~m}$. While four layers appear from $20 \mathrm{~m}$ until $80 \mathrm{~m}$, the three layers at $90 \mathrm{~m}$ and $100 \mathrm{~m}$ still confirmed that the injected surfactant concentration can provide homogenous mixture at $100 \mathrm{~m}$ pipe length. The isosurface contour for $2 \%$ surfactant concentration is illustrated in figure 4(c).This was taken at 
position from $20 \mathrm{~m}$ to $100 \mathrm{~m}$.Four layers was seen initially, but gradually disappear with increased length. The homogenous mixture occur at the position where only one colour is seen, and it occurred at $72 \mathrm{~m}$ pipe length with this concentration.

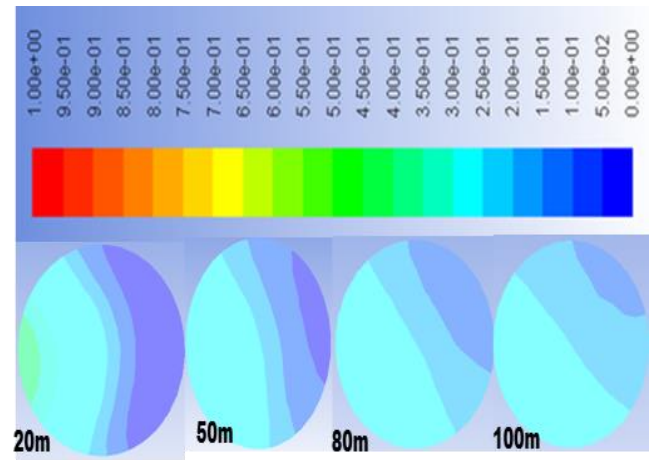

(a)

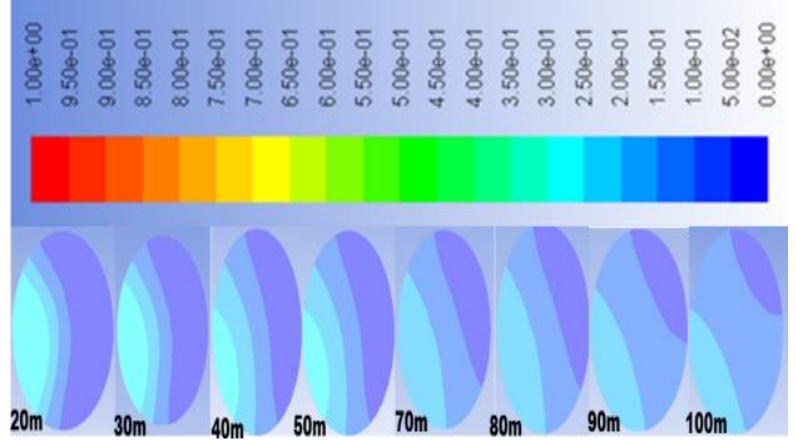

(b)

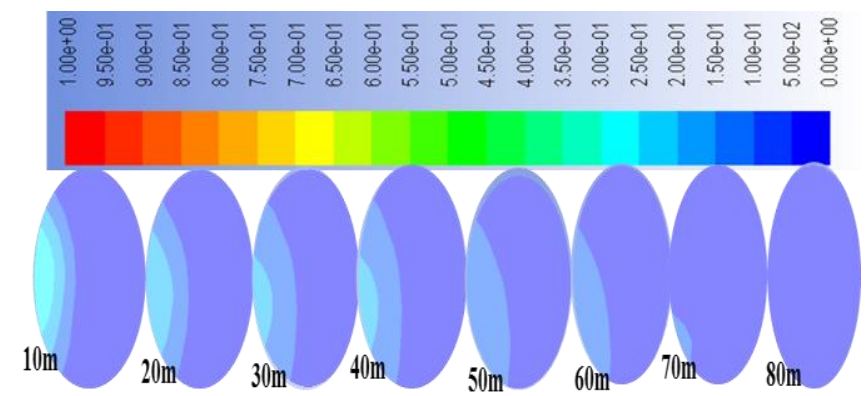

(c)

Figure 4. (a) Effect of position on calculated cross-sectional phase distributions for a $10 \%$ surfactant concentration. (b) Effect of position on calculated cross-sectional phase distributions for a $5 \%$ surfactant concentration. (c) Effect of position on calculated cross-sectional phase distributions for a $2 \%$ surfactant concentration.

\subsection{Pressure profile}

Pressure drop in two-phase flow is a critical design parameter in computational fluid dynamics that governs the pumping power required to transport fluids. Variation of pressure differences of the Surfactant brine mixture along the radial direction for three surfactant concentrations such as $10 \%, 5 \%$ and $2 \%$ is shown in figure 7 . The figure shows that pressure drop for every surfactant concentration decreases radially across the pipe geometry. This is consistent with the result of [16] in the literature. 


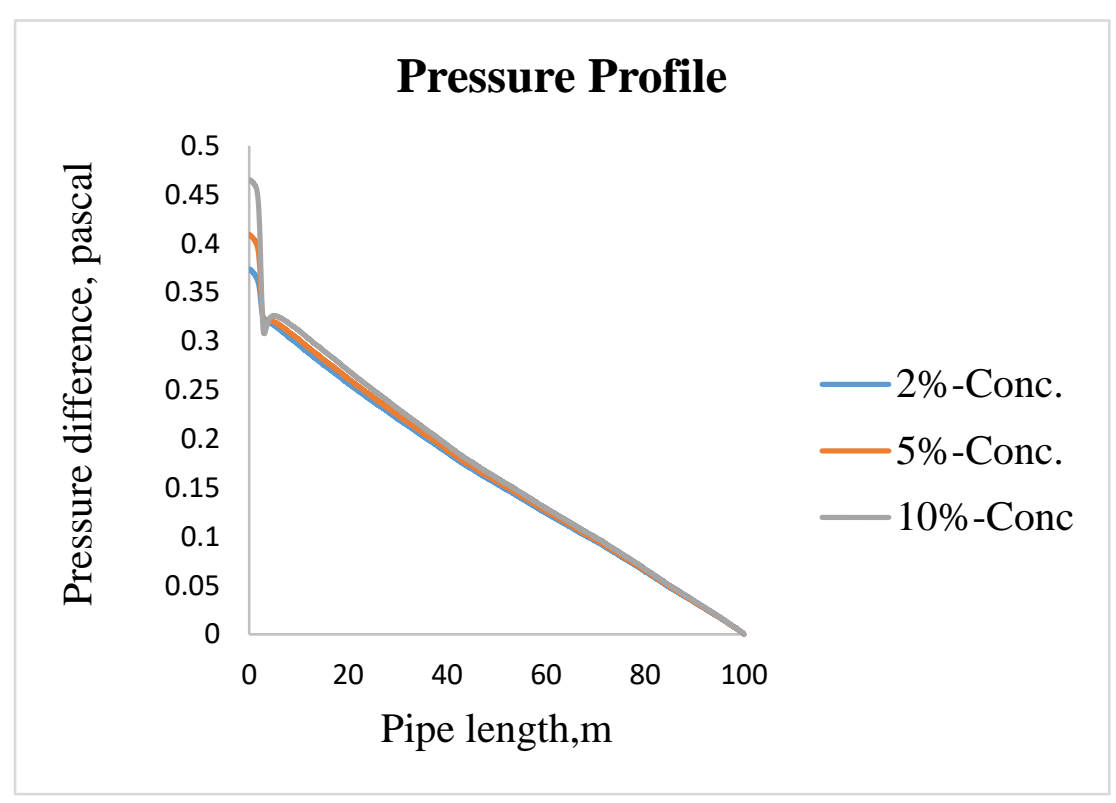

Figure 5. The pressure drop difference in radial direction for surfactant brine mixing.

\subsection{Velocity Profile}

Radial distribution of mixture velocity of stratified wavy and annular flow is shown in figure 6 . The mixing flow of surfactant-bine is driven by turbulent flow, especially from the Tjunction point. Therefore, the mixture velocity is highest at the junction where surfactant is injected to mix with brine flow at about $1 \mathrm{~m}$ from inlet. The mixing velocity apparently assume parabolic shape between $20 \mathrm{~m}$ and $50 \mathrm{~m}$ pipe and become uniform at $56 \mathrm{~m}$. The velocity for $2 \%$ concentration is quite perfect at range of $70 \mathrm{~m}$ until $100 \mathrm{~m}$, signifying homogeneity. This result is perfectly consistent with [17] work reported on water-ethanol mixing in channel using CFD.

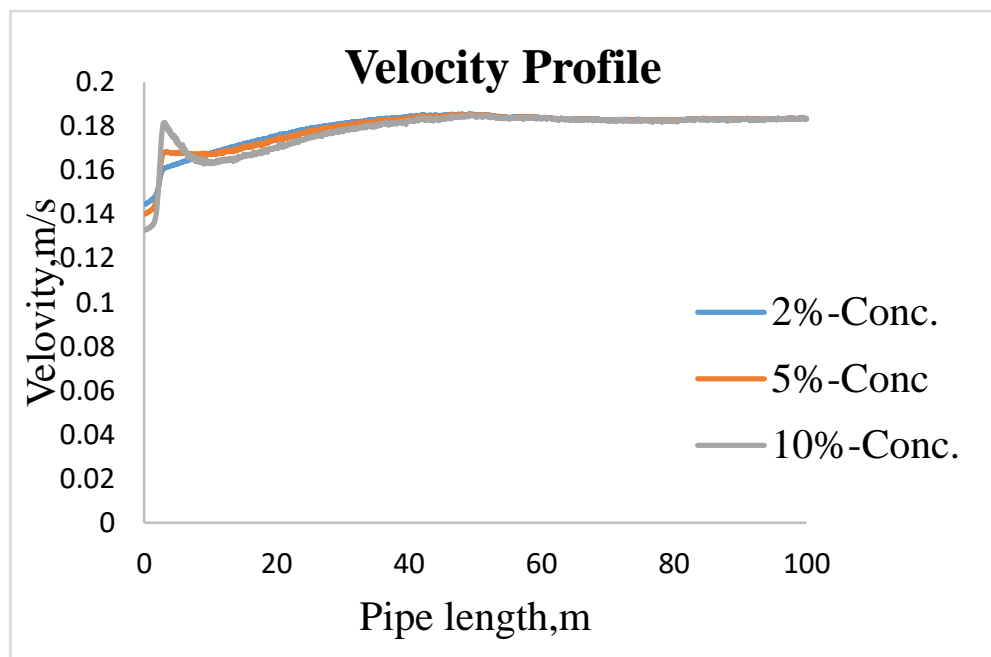

Figure 6. The velocity profile for radial distribution of surfactant brine mixing.

\subsection{Surfactant mole fraction}

The mole fraction, known as specie in computational fluid dynamics (CFD) is one of the crucial parameters used to characterize two-phase flows. It is an essential the key physical value that could enable make it possible for other critical parameters such as phase density, phase viscosity, relative average velocity to be determined. The radial behavior of surfactant mole fraction for mixing concentrations such as $10 \%, 5 \%$ and $2 \%$ is illustrated in figure 7 . It can been 
seen that the same trend is flowed by all surfactant concentration. Due to turbulent a curve is formed between 10 and $20 \mathrm{~m}$ of the pipe length which gradually diminished as the mixing continue along the pipe length. This level of the cure curve is difference with different concentration of surfactant in the mixtutre.it is highest in $10 \%$ concentration while $2 \%$ concentration showed lowest.In the $2 \%$ concentration a linearity is visible at around $70 \mathrm{~m}$ of the pipe, showing homogenous mixture is achieved. The pattern followed is quite consistent with the result of Gianni O. et al [17] .

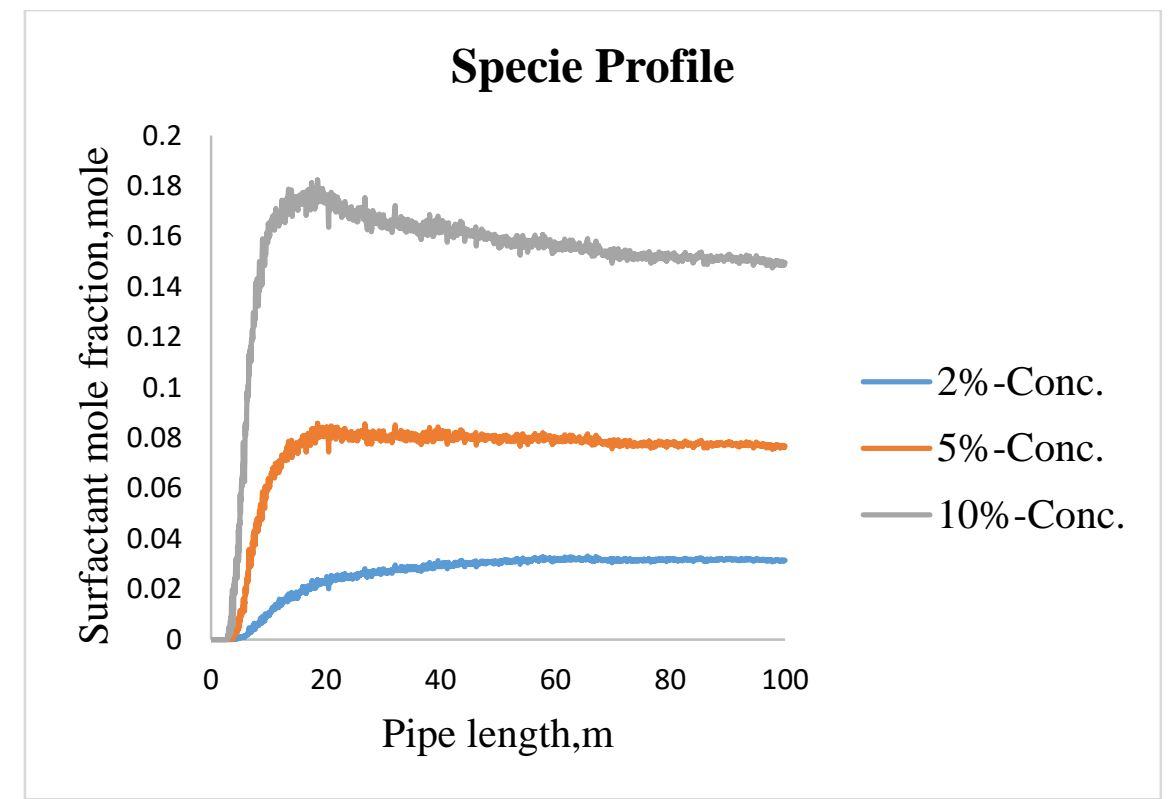

Figure 7. The radial distribution of surfactant mole fraction for different concentration.

\subsection{Mixing Time Determination}

The time which two or more flowing fluid attain homogeneity in the mixer is basically know as mixing time. It is an essential parameter for optimization of the mixing process.in this study, sensitivity analysis has shown that only $2 \%$ surfactant concentration can provide homogenous mixture of surfactant brine mixing in $100 \mathrm{~m}$ pipe length. Therefore, the plot of time position of the $2 \%$ surfactant is shown in figure 8 to determine the mixing time at the length which homogenous mixture is obtained (i.e. $72 \mathrm{~m}$ ).

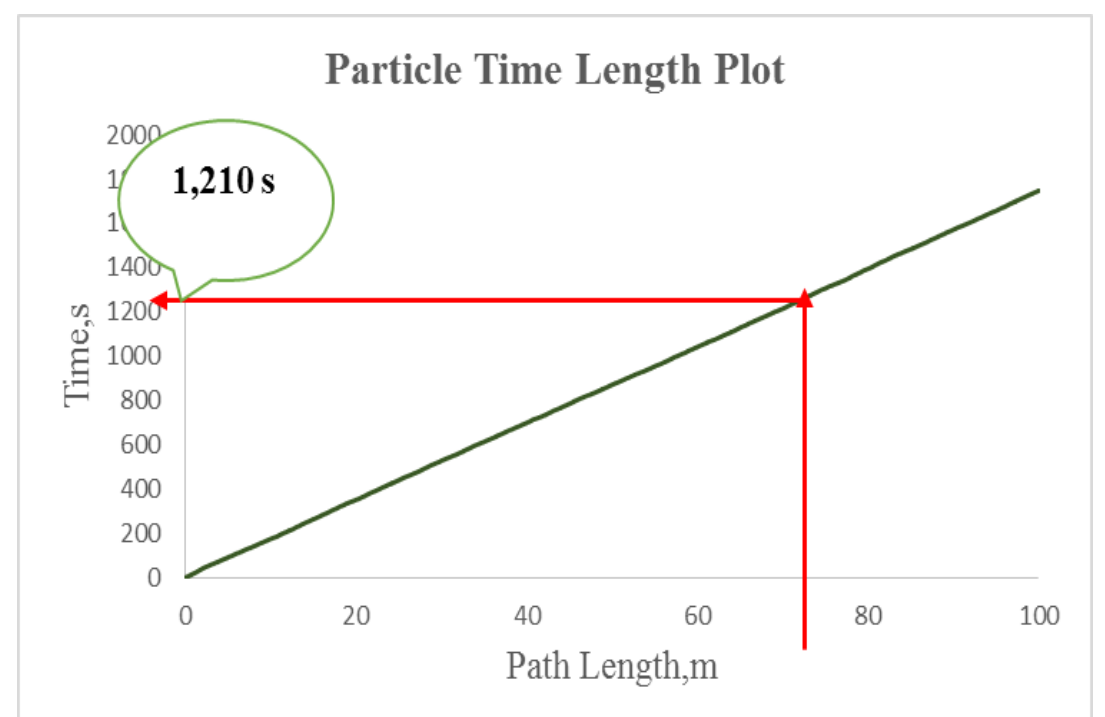

Figure 8. The plot of particle time-length for $2 \%$ surfactant concentration. 


\section{Conclusion}

In this study, detailed computational fluid dynamics (CFD) has been carried out on Surfactant-Brine mixing in horizontal pipe for Enhance Oil Recovery surface facility in Tanjung oil field, Indonesia. Numerical simulations were performed to study the flow fields and mixing characteristics of liquid flows converging in a T-shaped with boundary conditions based on the field flow rate which $650 \mathrm{bbl} /$ day of surfactant flooding at 400 psi pressure and temperature 63F. The diameters of the pipe inlets and outlet and $100 \mathrm{~m}$ length was designed for the liquidliquid flow. An unstructured tetrahedral mesh of the fluid volume was made using Grid Fluent Inc., Lebanon, and $\mathrm{NH}$. The mesh z. used for all subsequent computations in this analysis contains 685,432 nodes and 3,530,488 first-order tetrahedral elements. The result obtained has been subjected to rigorous sensitivity analysis to ensure the integrity of the result. The result matched well with the result of literature. The mixing times and time dependent dynamic viscosities of the liquid mixture with different viscosities and different densities can be predicted by CFD simulation. The high viscosity liquid mixture also has a great effect on an observed flow field that is predicted by CFD simulation. The time to achieve homogenous mixture of surfactant-brine for $2 \%$ surfactant concentration in the geometry propertied under designed is 1210 second which translates to 20 minutes mixing time. The mixing length for the under designed geometry properties for mixing surfactant-bring with $2 \%$ concentration is $72 \mathrm{~m}$.

Author Contributions: Taufan Marhaendrajana provided the conceptualization of this study; the methodology was designed and experimented by Abdulmumuni Aliyu; the Software was provided by Yazid Bindar.; Taufan Marhaendrajana and Yazid Bindar validated the result as the simulation progresses; the research analysis was performed by Abdulmumuni Aliyu.; Abdulmumuni Aliyu carried out all the investigation throughout the study.Taufan Marhaendrajana provided the resources used in the research; Yazid Bindar oversaw Data Curation; the Original Draft was Prepared by Abdulmumuni Aliyu; Abdulmumuni Aliyu conducted the Writing, Reviewed by Yazid Bindar while Taufan Marhaendrajana Edited the article; Taufan Marhaendrajana did the Supervision.; the Project Administration was carried out by Taufan Marhaendrajana.

Funding: Please add: This research received no external funding.

\section{Acknowledgement}

The work was done at EOR laboratory, energy building of the Oil and Gas Recovery Indonesia, Institute of Technology Bandung. The authors are grateful to research laboratory of the department of chemical engineering, institute of technology, Bandung, for providing AnsysFluent software and there hospitality during this research. Our sincere appreciation to Department of Petroleum, ITB, for permission to publish the work.

Conflicts of Interest: The authors declare no conflict of interest.

\section{References}

1. Carlos, R. CFD analysis of flow field in a mixing tank with and without baffles, Master's, Thesis In Mechanical, Rochester Institute of Technology Rochester, New York, USA, 1996.

2. Venkateswara, K. R.; RamaKrishna, V.V; Subrahmanyam, V. Comparison of CFD Simulation of Hot and Cold Fluid Mixing In T-Pipe by Placing Nozzle at Different Places, IJRET, 2014,Vol:03,pg 2319-1163,http://www.ijret.org.

3. Tamer, N.; Imam, E.;Kamal, E. Sand-Water Slurry Flow Modelling In A Horizontal Pipeline By Computational Fluid Dynamics Technique, IWTJ, 2014, Vol. 4,No. 1. 
4. Zalc, J. M.; Szalai, E. S.; Muzzio, F. J. Characterization of Flow and Mixing in an SMX Static Mixer, JAICE, 2002, Vol. 48, pg 45202.

5. Eswara, K.; Naveen, J.; Nagaraju, M.;Diwakar, V. Analysis of Fluid Structure Interaction in Mixing Fluids, IJMER, 2015,Vol. 3, pg 2321-5747.

6. Abdolkarimi, V.; Ganji, H. CFD Modeling of Two Immiscible Fluids Mixing In A Commercial Scale Static Mixer, BJCE, 2014, Vol. 31, pp. 949 - 957, DOI: 10.1590101046632.20140314s00002857.

7. Joanna, K.; Monika, M.; Marcelina, B.;Marek, D. CFD Modelling of the Fluid Flow Characteristics in an External-Loop Air-Lift Reactor, IACE, 2013,vol. 32,pg 1435-1440,DOI: 10.3303/CET1332240.

8. Ansys,inc. ANSYS Solver Theory Guide,North America,USA, 2013.

9. Edwards, M.F.; Harnby,N.; Nienon, A.W. Textbook of Mixing in Process Industries, second edition, Oxford Aukland, Boston, 1997.

10. Fawzi, A. A. Mixing of Two Miscible Liquids with High Viscosity and Density Difference in Semi-Batch and Batch Reactors, CFD Simulations and Experiments, Doctoral dissertation, University of Duisburg-Essen, Germany, 2007.

11. Bidhan, K. P. Computational Fluid Dynamics Analysis of Flow through High Speed Turbine Using Fluent, BEng. thesis in Mechanical Engineering, institute of technology Rourkela,India, 2013.

12. Athulya, A.S.; Miji, C. R. CFD Modelling of Multiphase Flow through T Junction, ICETEST, 2016, vol. 24, pg.325 - 331,DOI:10.1016/j.protcy.2016.05.043.

13. Barth, T.; Jespersen, D. The design and application of upwind schemes on unstructured meshes, NASAARC, 1989.

14. Patankar, S. V. Textbook on Numerical Heat Transfer and Fluid Flow, Electro Skills Series, the University of California,USA,1980, pg. 197,ISSN 0272-4804,

15. Ranade, V.V. Computational Flow Modelling for Chemical Reactor Engineering, Academic Press, New York, USA, 2002.

16. Anand, B.; Desamala, A.K.; Dasamahapatra, T.; Mandal, K. Oil-Water Two-Phase Flow Characteristics in Horizontal Pipeline - A Comprehensive CFD, IJCMNMME, 2014,Vol. 8,pg 4,scholar.waset.org/1992/9999287.

17. Gianni, O.; Chiara, G.; Elisabetta, B.; Roberto, M. Mixing of Two Miscible Liquids in TShaped Micro devise,IACE,2013,Vol. 32, pg 1471-1476,DOI:10.3303(CET1342246). 